\title{
MicroRNA-146a-5p alleviates lipopolysaccharide-induced NLRP3 inflammasome injury and pro-inflammatory cytokine production via the regulation of TRAF6 and IRAK1 in human umbilical vein endothelial cells (HUVECs)
}

\author{
Jingyuan Hou ${ }^{1,2,3 \#}$, Qiaoting Deng ${ }^{1,3,4 \#}$, Xunwei Deng ${ }^{2,3,4}$, Wei Zhong ${ }^{1}$, Sudong Liu ${ }^{1,2}$, Zhixiong Zhong ${ }^{1}$ \\ ${ }^{1}$ Meizhou Academy of Medical Sciences Cardiovascular Disease Research Institute, Meizhou People's Hospital, Meizhou, China; ${ }^{2}$ Guangdong \\ Provincial Key Laboratory of Precision Medicine and Clinical Translational Research of Hakka Population, Meizhou, China; ${ }^{3}$ Guangdong Provincial \\ Engineering and Technology Research Center for Molecular Diagnostics of Cardiovascular Diseases, Meizhou, China; ${ }^{4}$ Guangdong Provincial \\ Engineering and Technological Research Center for Clinical Molecular Diagnosis and Antibody Drugs, Meizhou, China \\ Contributions: (I) Conception and design: Z Zhong, J Hou, S Liu; (II) Administrative support: Z Zhong; (III) Provision of study materials or patients: \\ W Zhong; (IV) Collection and assembly of data: Q Deng, X Deng; (V) Data analysis and interpretation: J Hou, Q Deng; (VI) Manuscript writing: \\ All authors; (VII) Final approval of manuscript: All authors. \\ \#These authors contributed equally to this work. \\ Correspondence to: Zhixiong Zhong; Sudong Liu. Meizhou Academy of Medical Sciences Cardiovascular Disease Research Institute, Meizhou People's \\ Hospital, No. 63 Huangtang Road, Meijiang District, Meizhou 514031, China. Email: zhongzhixiong@mzrmyy.com; vanguard_1987@163.com.
}

Background: Microribonucleic acids (miRNAs) have an evident role in regulating endothelial inflammation and dysfunction, which characterizes the early stages of atherosclerosis. The NOD-like receptor family pyrin domain-containing protein 3 (NLRP3) inflammasome has been reported to contribute to the endothelial inflammatory response that promotes atherosclerosis development and progression. This study sought to investigate the effects of miR-146a-5p on lipopolysaccharide (LPS)-induced NLRP3 inflammasome injury and pro-inflammatory cytokine production in human umbilical vein endothelial cells (HUVECs).

Methods: HUVECs were transfected with a miR-146a-5p mimic, small-interfering RNA (siRNA) (siTRAF6, and si-IRAK1), and were then stimulated with LPS for $24 \mathrm{~h}$. The messenger (mRNA) and the protein levels of $\mathrm{p}-\mathrm{NF}-\kappa \mathrm{B} / \mathrm{NF}-\kappa \mathrm{B}, \mathrm{NLRP} 3$, Caspase-1, pro-inflammatory cytokine [interleukin (IL)-6, IL-1 $\beta$ and tumor necrosis factor alpha (TNF- $\alpha)]$ in the HUVECs were analyzed by quantitative real-time polymerase chain reactions (PCRs) and western blot assays, respectively. The secretion of IL-6 from the cells was detected by enzyme-linked immunoassay (ELISA). Bioinformatic and dual-luciferase reporter assays were performed to identify the targets of miR-146a-5p.

Results: LPS promoted pro-inflammatory cytokine expression in a dose-dependent manner and significantly increased the expression levels of $\mathrm{p}-\mathrm{NF}-\kappa \mathrm{B} / \mathrm{NF}-\kappa \mathrm{B}$ p65, NLRP3, and Caspase-1. After transfection with a miR-146a-5p mimic, or si-TRAF6 or si-IRAK1, we observed that the mRNA and protein levels of NF- $\kappa \mathrm{B} / \mathrm{p}-\mathrm{NF}-\kappa \mathrm{B}, \mathrm{NLRP} 3$, Caspase-1, and pro-inflammatory cytokine in the HUVECs were all down-regulated, and the secretion of IL-6 from cells declined significantly. After transfection with a miR-146-5p mimic, the expression of TRAF6 and IRAK1 in HUVECs were both down-regulated. Dualluciferase reporter assays confirmed that miR-146-5p directly targets the 3'-untranslated region (3'-UTR) of TRAF6 and IRAK1 to regulate their expression.

Conclusions: As a modulator of TRAF6 and IRAK1, miR-146a-5p negatively regulated LPS-induced NF$\kappa \mathrm{B}$ activation and the NLRP3 inflammasome signaling pathway in HUVECs. Thus, miRNA-146a-5p may serve as a potential therapeutic target for atherosclerosis. 
Keywords: MicroRNA-146a-5p; atherosclerosis; NLRP3 inflammasome; NF-кB; pro-inflammatory cytokine

Submitted Jul 14, 2021. Accepted for publication Aug 30, 2021.

doi: 10.21037/atm-21-3903

View this article at: https://dx.doi.org/10.21037/atm-21-3903

\section{Introduction}

Accounting for 17.3 million deaths per year globally, cardiovascular disease is one of the leading causes of mortality worldwide. Along with population growth, an aging population, and lifestyle changes, it is estimated that the number of deaths from cardiovascular disease will exceed 23.6 million by 2030 (1). Atherosclerosis (AS) is the common pathological basis of many cardiovascular diseases, including coronary heart diseases, myocardial infarction, and peripheral vascular diseases. Exposure to atherosclerosis risk factors, such as dyslipidemia or pro-inflammatory mediator, in the context of disturbed flow, activates the inflammatory process and perturbs the homeostatic properties of the endothelial cells (ECs), which triggers the initial steps of atherosclerosis $(2,3)$. Inflammatory activation and chronic endothelial damage are closely linked, and create a vicious cycle that leads to the processes that determine the initiation and progression of atherosclerosis. Thus, key molecules or the respective inflammatory signaling pathways responsible for the formation and development of atherosclerosis need to be identified, as they may subsequently provide new targeted treatment options that more effectively prevent cardiovascular disease $(4,5)$.

The NOD-like receptor family pyrin domain-containing protein 3 (NLRP3) inflammasome is an intracellular complex that includes the NLRP3 protein, apoptosisrelated speckle-like protein (ASC) and caspase-1 precursor, activates caspase- 1 and facilitates the maturation and secretion of pro-inflammatory cytokines interleukin-1 $\beta$ (IL$1 \beta)$ and IL-18, eventually induces inflammation $(6,7)$. A number of endogenous pathogenic signals exist abundantly in atherosclerotic lesions, such as oxidized low-density lipoprotein (ox-LDL) and cholesterol crystals, activate the NLRP3 inflammasome (8-10), which participate in the endothelial inflammatory response and contribute significantly to the development and progression of atherosclerosis (11). Research has shown that a deficiency of NLRP3 inflammasome pathway proteins in bone marrow significantly reduces the development of atherosclerotic lesions compared to that in $\mathrm{Ldlr}^{-/-}$mice with wild-type bone marrow transplantation (8). However, the mechanistic relationship between inflammation and atherosclerosis induced by NLRP3 inflammasome is poorly understood.

Microribonucleic acids (miRNAs) are endogenous small non-coding RNAs (17-25 nucleotides in length) that negatively regulate the post-transcriptional gene by directly binding to the 3 '-untranslated region (3'UTR) of the target gene $(12,13)$. A number of miRNAs that participate in the regulation of many cellular and developmental processes have been extensively studied $(14,15)$. In humans, differential miRNA expression patterns have been implicated in various diseases or pathological states, and different clinical sample types, such as salivary glands or peripheral blood mononuclear cells (PBMCs), have been analyzed $(16,17)$. Previous studies have suggested that miR-146a plays an important role in regulating the inflammatory response. For example, research has shown that miR-146a attenuates cytokine signaling by impairing the nuclear factor- $\kappa \mathrm{B}(\mathrm{NF}-\kappa \mathrm{B})$ pathway in human hepatic stellate cell (18). Additionally, the expression level of miR146a was significantly increased in human monocytes by lipopolysaccharide, tumor necrosis factor alpha (TNF- $\alpha$ ), and IL-1 $\beta$ (19). In recent years, studies have shown that some miRNAs play a significant role in driving endothelial inflammation and may represent a promising therapeutic approach for atherosclerosis $(20,21)$. Additionally, miR$146 \mathrm{a}-5 \mathrm{p}$ has been found to be involved in the regulation of inflammation and cardiac energy metabolism (22), which suggests that it may be a promising therapeutic approach for atherosclerosis. In the present study, we demonstrated that miR-146a-5p alleviated lipopolysaccharide (LPS) induced NLRP3 inflammasome injury and pro-inflammatory cytokine secretion by down-regulating tumor necrosis factor receptor associated factor 6 (TRAF6) and interleukin1-receptor-associated kinase 1 (IRAK1) in human umbilical vein endothelial cells (HUVECs).

We present the following article in accordance with the MDAR reporting checklist (available at https://dx.doi. org/10.21037/atm-21-3903). 
Table 1 The primer sequences of quantitative real-time polymerase chain reaction (qPCRs)

\begin{tabular}{ll}
\hline Gene name & Sequences \\
\hline GAPDH & Forward: 5'-ATGACATCAAGAAGGTGGTG-3' \\
& Reverse: 5'-CATACCAGGAAATGAGCTTG-3' \\
NF- $k B$ & Forward: 5'-ATGCTCAGGAGCCCTGTAATG-3' \\
& Reverse: 5'-CCCCACACTTCAACAGGAGT-3' \\
NIrp3 & Forward: 5'-GTGTTTCGAATCCCACTGTG-3' \\
& Reverse: 5'-TCTGCTTCTCACGTACTTTCTG-3' \\
Caspase-1 & Forward: 5'-TTGAAGGACAAACCGAAGG-3' \\
& Reverse: 5'-GGAAGAGCAGAAAGCGATAA-3' \\
IL-1 $\beta$ & Forward: 5'-ATGCACCTGTACGATCACTGA-3' \\
& Reverse: 5'-ACAAAGGACATGGAGAACACC-3' \\
IL-6 & Forward: 5'-TGCAATAACCACCCCTGACC-3' \\
& Reverse: 5'-ATTTGCCGAAGAGCCCTCAG-3' \\
TNF- $\alpha$ & Forward: 5'-TGCACTTGGAGTGATCGGC-3' \\
UiR-146a-5p & Forward: 5'-TGAGAACTGAATTCCATGG-3' \\
\hline & Reverse: 5'-ACTCGGGGTTCGAGAAGATG-3' \\
& Forward: 5'-GGAACGATACAGAGAAGATTAGC-3' \\
& Reverse: 5'-TGGAACGCTTCACGAATTTGCG-3' \\
&
\end{tabular}

\section{Methods}

\section{Patients}

Peripheral blood monouclear cells (PBMCs) were collected from 40 patients, including 20 acute myocardial infarction (AMI) patients and 20 normal coronary artery (NCA) patients, who were admitted to Meizhou People's Hospital (Huangtang Hospital) between June 2017 and December 2017. AMI was defined according to the 2012 Joint ESC/ACCF/AHA/WHF Task Force on the Third universal definition of myocardial infarction (23). NCA patients were defined as no stenosis in coronary arteries by coronary angiography and served as controls in this study. All procedures in this study were in accordance with the ethical guidelines outlined in the Helsinki Declaration (as revised in 2013) and complies with the Ethics Committee of Meizhou People's Hospital (No. 2018-C-11). Signed informed consent was obtained from each participant at the time of enrollment.

\section{Cell culture}

HUVECs were obtained from the Chinese Academy of Sciences Cell Bank (Shanghai, China). The cells were maintained in endothelial cell medium (Sciencell Research Laboratories, 1001) supplemented with endothelial cell growth supplement, $5 \%$ fetal bovine serum, and $1 \%$ penicillin/streptomycin. The cells were incubated at $37^{\circ} \mathrm{C}$ under $5 \%$ carbon dioxide $\left(\mathrm{CO}_{2}\right)$ in Thermo Scientific ${ }^{\mathrm{TM}}$ Steri-Cycle $\mathrm{CO}_{2}$ incubators.

\section{Transfection}

The HUVECs were seeded in a 12 -well plate 1 day in advance. The $30 \mathrm{nM}$ miR-146a-5p mimic and negative control (mimic NC) were transfected into cells using Lipofectamine $^{\mathrm{TM}} 3000$ Transfection Reagent (ThermoFisher, Invitrogen, L3000015) for $48 \mathrm{~h}$ in accordance with the manufacturer's recommendations. $50 \mathrm{nM}$ of TRAF6 and IRAK1 small-interfering RNA (siRNA), and a negative control were transfected into the cells in the same manner. No obvious cytotoxicity was observed in the transfected cells using Lipofectamine ${ }^{\mathrm{TM}} 3000$ Transfection Reagent. The cells were then cultured for an additional $24 \mathrm{~h}$ with $100 \mathrm{ng} / \mathrm{mL}$ of LPS (Sigma-Aldrich) to collect RNA, protein, or cellular supernatant.

\section{Quantitative real-time PCR}

Total RNA was isolated from the cell lysates using TRIzol reagent (Tiangen, DP430) in accordance with the manufacturer's instructions. A PrimeScript RT reagent Kit (TaKaRa, RR047) and Mir-X miRNA First-Strand Synthesis Kit (TaKaRa, 638313) were used to synthesize complementary deoxyribonucleic acid (cDNA) for the mRNA or miRNA analyses. TB Green Premix Ex Taq. II (TaKaRa, RR820) and TB Green Advantage qPCR Premix (TaKaRa, 639676) were used to amplify the desired gene or miRNA, respectively. Quantitative real-time polymerase chain reactions (qPCRs) were conducted using a 7500 RealTime PCR System (Applied Biosystems). Glyceraldehyde3-phosphate dehydrogenase (GAPDH) and U6 served as the internal controls for the mRNA and miRNA detection, respectively. Table 1 shows the primer sequences of all the detected genes. No amplifications of the nonspecific products were observed in the dissociation curve 
of the reaction. The data were normalized to GAPDH or U6 expression levels, and the relative expression levels of the genes were calculated using $2^{-\Delta \Delta \mathrm{Ct}}$ method, where Ct represents the threshold cycle. Three independent experiments were conducted.

\section{Western blot}

Protein samples $(20 \mu \mathrm{g})$ were separated by sodium dodecylsulfate polyacrylamide gel electrophoresis (SDS-PAGE), and the proteins were then transferred into polyvinylidene fluoride blots. After being blocked by $5 \%$ milk, the blots were incubated with an antibody against target proteins at

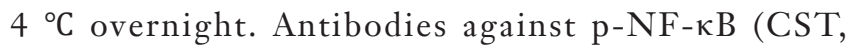
\#3033) was obtained from Cell Signaling Technology (Danvers, MA). Antibodies against NF- $\kappa \mathrm{B}$ antibody (ab16502), NLRP3 (ab214185), Caspase-1 (ab207802), IL-1ß (ab229696), TRAF6 (ab40675), IRAK1 (ab238) were purchased from Abcam (Cambridge, UK). The $\alpha$-Tubulin antibody (Sigma, T5168) was incubated as a loading control. These blots were further incubated with horseradish peroxidase (HRP)-conjugated secondary antibody (Abcam, ab6789 and ab6721), and exposed on a ChemiDoc MP imaging system (BIO-RAD) with an enhanced chemiluminescence (ECL) solution.

\section{ELISA}

After miRNA mimic or siRNA transfection, the HUVECs were stimulated with LPS $(100 \mathrm{ng} / \mathrm{mL})$ for $24 \mathrm{~h}$, and cellular supernatant was then collected for the enzymelinked immunoassay (ELISA). A human IL-6 ELISA kit (Dakewe Biotech, Shenzhen, China) was used to detect the IL-6 concentration. ELISA was performed in accordance with the manufacturer's instructions. Three independent experiments were conducted, and a standard curve was included in each experiment.

\section{Luciferase reporter assays}

The HEK293 cells were seeded into a 12-well plate and incubated overnight to achieve approximately $80 \%$ confluence. A TRAF6/IRAK1-luciferase-reporter recombinant plasmid (psiCHECK2-TRAF6/IRAK1 3'-UTR vector), containing 2 miR-146a-5p binding motifs, was transfected into HEK293 cells together with miR-146a-5p mimic or mimic NC using
Lipofectamine 3000 (Invitrogen). As the control, recombinant plasmid (psiCHECK2-TRAF6/IRAK1 3'-UTR mutant vector), without miR-146a-5p binding motifs, was transfected into the HEK293 cells in the same manner. After transfection for $24 \mathrm{~h}$, the cell lysates were obtained to detect the luciferase activity using a Dual-Luciferase Reporter Assay System (Promega, E1910, Madison, WI). The results are presented as the relative luciferase activity (the ratio of Renilla luciferase to Firefly luciferase).

\section{Quantification and statistics}

SPSS software 20.0 was used to conduct the statistical analysis. Image J software (NIH, Bethesda, MD) was used to analyze the exposure intensity of the targeted blots. Prizm software 6.0 (GraphPad Software) and Adobe Illustrator CS6 were used to draw and edit the charts. All the data are presented as the mean \pm standard deviation (SD). The qPCR, Western blot, and ELISA data were analyzed by the non-parametrical Mann-Whitney $U$ test (2 groups) or the Kruskal-Wallis test (more than 2 groups). A $\mathrm{P}<0.05$ was considered statistically significant.

\section{Results}

\section{LPS-induced inflammation injury and miR-146a-5p expression in HUVECs}

First, we compared the expression of miR-146a-5p in PBMCs obtained from AMI patients and NCA patients by qPCRs. The mean age of the AMI patients was $65.2 \pm 7.6$ years, $70 \%$ $(n=14)$ patients were males, and the mean age of the NCA patients was $64.8 \pm 12.9$ years, $75 \%(\mathrm{n}=15)$ were males, respectively. The AMI patients had a higher expression level of miR-146a-5p than the HC patients (see Figure 1A). It is well known that inflammatory activation has a critical role in AS development and cardiovascular diseases. In the present study, LPS was used as an inflammatory stimulant, and the HUVECs were treated with different concentrations of LPS $(0,25,50,100,200$, or $500 \mathrm{ng} / \mathrm{mL})$. We further investigated the expression of miR-146a-5p and pro-inflammatory cytokines (IL-6, IL-1 $\beta$ and TNF- $\alpha$ ) in LPS-treated HUVECs. Compared to the untreated cells, the expression levels of miR-146a-5p and pro-inflammatory cytokine were elevated significantly following $25 \mathrm{ng} / \mathrm{mL}$ of LPS treatment for $24 \mathrm{~h}$ in the HUVECs (see Figure 1B,1C). 

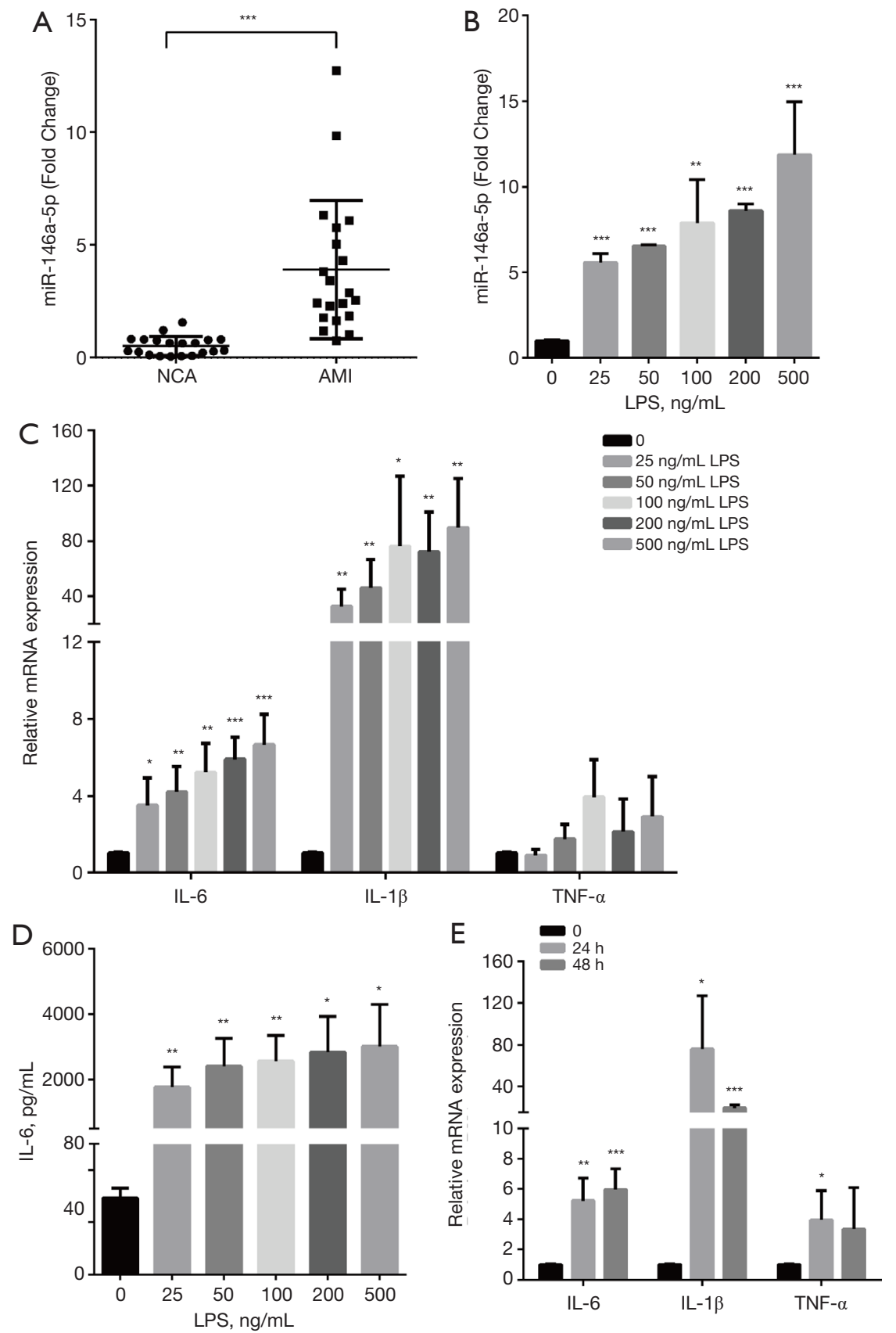

Figure 1 LPS-induced inflammation injury and miR-146a-5p expression in HUVECs. (A) Comparisons of miR-146a-5p levels between AMI patients ( $n=20)$ and NCA patients ( $n=20)$; (B) miR-146a-5p expression in HUVECs was detected by qPCRs after treatment with different concentrations of LPS (0-500 ng/mL) for $24 \mathrm{~h}$; (C) the mRNA level of pro-inflammatory cytokine (IL-1 $\beta$, IL-6, and TNF- $\alpha$ ) in LPS-treated HUVECs for 24 h; (D) the secretion level of IL-6 from the HUVECs was examined by ELISA after treatment with LPS for 24 h; (E) the HUVECs were treated with $100 \mathrm{ng} / \mathrm{mL}$ LPS for 24 or $48 \mathrm{~h}$, and qPCRs were then used to detect the mRNA expression level of the proinflammatory cytokine. * $\mathrm{P}<0.05 ;{ }^{* *}, \mathrm{P}<0.01$; ${ }^{* * *}, \mathrm{P}<0.001$ s. the control group $(0 \mathrm{ng} / \mathrm{mL}$ LPS). LPS, lipopolysaccharide; HUVECs, human umbilical vein endothelial cells; AMI, acute myocardial infarction; NCA, normal coronary artery; IL-1 $\beta$, interleukin-1 $\beta$; IL-6, interleukin-6; TNF- $\alpha$, tumor necrosis factor alpha; qPCRs, quantitative real-time polymerase chain reactions. 

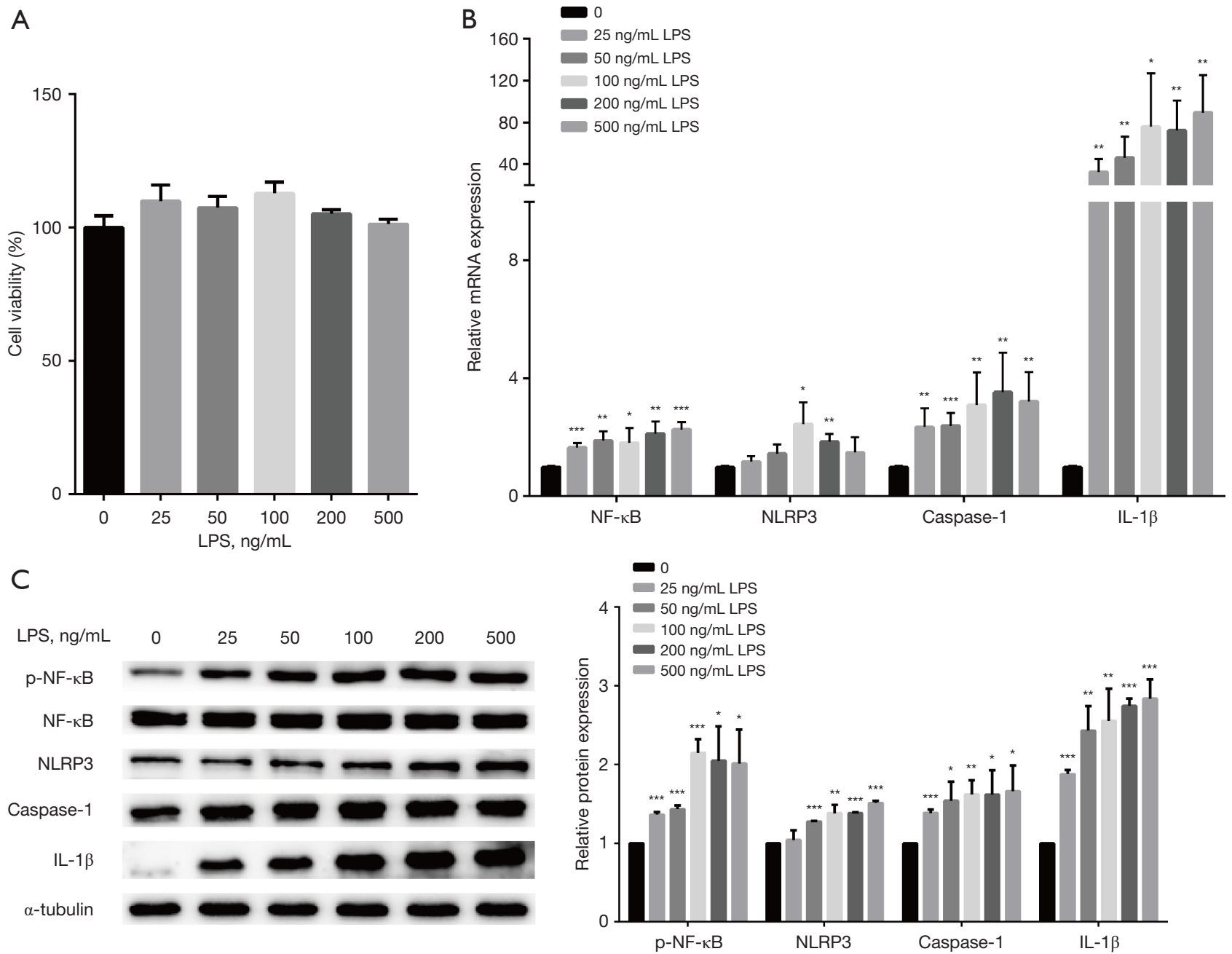

Figure 2 Regulation of the NF- $\mathrm{kB} / \mathrm{NLRP} 3$ signaling pathway in HUVECs stimulated with LPS. (A) The cell viability of HUVECs was detected by Cell Counting Kit- 8 after treatment with LPS for $24 \mathrm{~h}$; (B) the HUVECs were treated with LPS for 24 h, and qPCRs were then used to detect the mRNA expression levels of NF- $\kappa B$, NLRP3, Caspase-1, and IL-1 $\beta$ and (C) the protein levels of NF- $\kappa B$, phospho-NF- $\kappa B$,

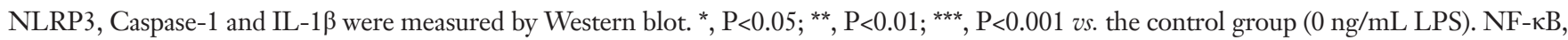
nuclear factor- $\kappa \mathrm{B}$; NLRP3, NOD-like receptor family pyrin domain-containing protein 3; HUVECs, human umbilical vein endothelial cells; LPS, lipopolysaccharide; qPCRs, quantitative real-time polymerase chain reactions; IL-1 $\beta$, interleukin-1 $\beta$.

The secretion of interleukin-6 (IL-6) from the HUVECs was significantly increased after LPS treatment for $24 \mathrm{~h}$ (see Figure 1D). Further, HUVECs were treated with $100 \mathrm{ng} / \mathrm{mL}$ LPS for 24 or $48 \mathrm{~h}$, and the mRNA expression level of the pro-inflammatory cytokine were detected (see Figure 1E). LPS was shown to promote pro-inflammatory cytokine expression in a dose-dependent manner (with an optimum concentration of $100 \mathrm{ng} / \mathrm{mL}$ for $24 \mathrm{~h}$ ).

\section{Regulation of the NF-кB/NLRP3 signaling pathway in HUVECs stimulated with LPS}

Next, the HUVECs were stimulated with LPS for $24 \mathrm{~h}$, the cell viability and NLRP3 inflammasome were then detected. No significant inhibition was observed in the cell viability of the HUVECs after LPS treatment (see Figure 2A). Further, the mRNA and the protein levels of $\mathrm{p}-\mathrm{NF}-\mathrm{kB} /$ 

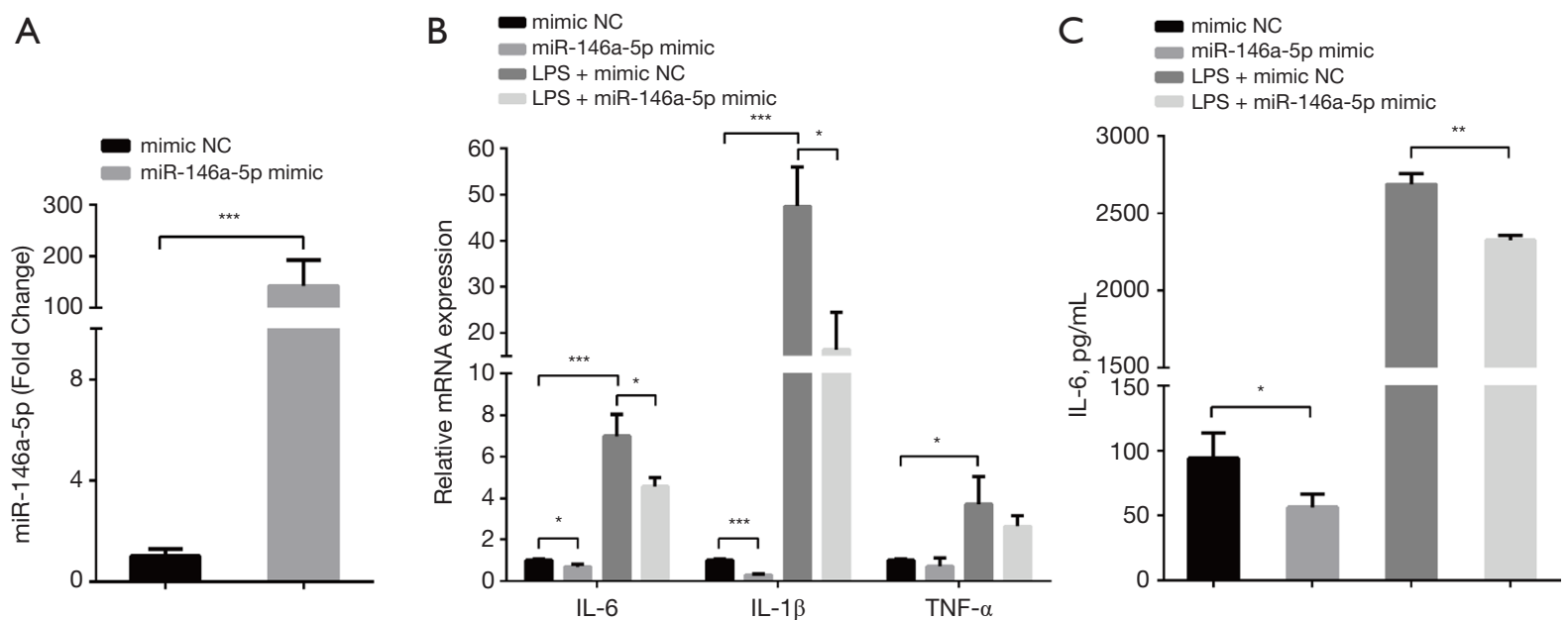

Figure 3 Overexpression of miR-146a-5p reduced LPS-induced pro-inflammatory cytokine expression and secretion. (A) The HUVECs transfected with a miR-146a-5 mimic for $48 \mathrm{~h}$; the expression level of miR-146a-5p was detected by qPCR, (B) after the overexpression of miR-146a-5p, the HUVECs were treated with $100 \mathrm{ng} / \mathrm{mL}$ LPS for $24 \mathrm{~h}$, and qPCRs were then used to detect the mRNA expression levels of pro-inflammatory cytokine, and $(\mathrm{C})$ the secretion level of IL-6 from HUVECs was measured via ELISA. *, $\mathrm{P}<0.05$; **, $\mathrm{P}<0.01$; ***, $\mathrm{P}<0.001$. LPS, lipopolysaccharide; HUVECs, human umbilical vein endothelial cells; qPCR, quantitative real-time polymerase chain reaction; IL-6, interleukin-6; ELISA, enzyme-linked immunoassay; NC, negative control.

NF- $\kappa$ B, NLRP3, Caspase-1, and IL-1 $\beta$ were significantly increased in LPS-treated cells than untreated cells (see Figure 2B,2C). These results showed that LPS regulated the NF- $\mathrm{KB} / \mathrm{NLRP} 3$ signaling pathway in HUVECs.

\section{Overexpression of miR-146a-5p reduced LPS-induced pro- inflammatory cytokine expression and secretion}

After transfection with a miR-146a-5p mimic for $48 \mathrm{~h}$, the expression of miR-146a-5p was significantly up-regulated in the HUVECs (see Figure $3 A$ ). The overexpression of miR146a-5p led to a significant decrease in the mRNA levels of IL- $1 \beta$ and IL- 6 in the HUVECs regardless of whether the cells were subject to LPS treatment or not (see Figure $3 B$ ). The overexpression of miR-146a-5p also caused a significant decline in the secretion of IL-6 in HUVECs (see Figure 3C). The results showed that miR-146a-5p overexpression in HUVECs led to a significant decrease in pro-inflammatory cytokine production.

MiR-146a-5p inbibited cytokine production by downregulating the $N F-\kappa B / N L R P 3$ signaling pathway

We then assessed whether miR-146a-5p overexpression inhibited pro-inflammatory cytokine expression by regulating the NF- $\mathrm{NB} / \mathrm{NLRP} 3$ signaling pathway. After transfection with a miR-146a-5p mimic for $48 \mathrm{~h}$, the HUVECs were treated with LPS. The mRNA expression of the NLRP3 inflammasome pathway genes were tested by qPCRs. The overexpression of miR-146a-5p led to a significant decrease in the mRNA levels of NF- $\mathrm{B}$, NLRP3, Caspase-1, and IL-1 $\beta$ regardless of whether the cells were subject to LPS treatment or not (see Figure $4 A$ ). The NF$\kappa \mathrm{B}$, phospho-NF- $\kappa \mathrm{B}$, NLRP3, Caspase-1, and IL-1 $\beta$ protein levels were measured by western blot assays. We found that miR-146a-5p overexpression also down-regulated the protein levels of phospho-NF- $\kappa$, NLRP3, Caspase-1, and IL- $1 \beta$ in the HUCVCs (see Figure $4 B$ ). These results implied that miR-146a-5p inhibited cytokines production by down-regulating the NF- $\mathrm{kB} / \mathrm{NLRP} 3$ signaling pathway.

\section{MiR-146a-5p down-regulated the NF-кB/NLRP3 signaling patbway by targeting the TRAF6 and IRAK1 gene}

We sought to confirm the potential mechanism by which miR-146a-5p alleviates LPS-induced NLRP3 inflammasome injury and pro-inflammatory cytokine secretion. TargetScan 


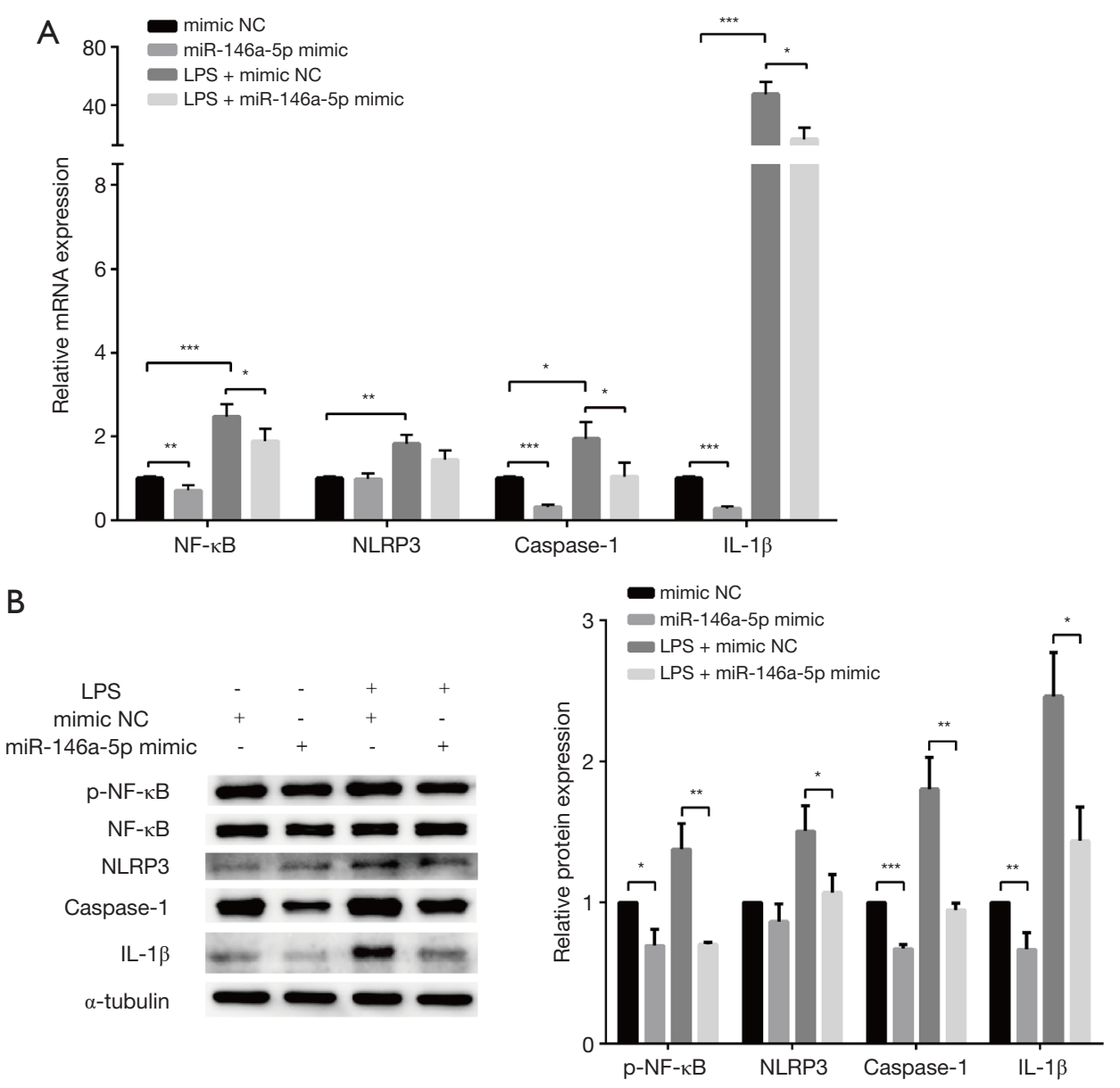

Figure 4 MiR-146a-5p inhibited cytokines production by down-regulating the NF- $\kappa \mathrm{B} / \mathrm{NLRP} 3$ signaling pathway. (A) After the overexpression of miR-146a-5p, the HUVECs were treated with $100 \mathrm{ng} / \mathrm{mL}$ LPS for $24 \mathrm{~h}$, and qPCRs were used to detect the mRNA expression levels of

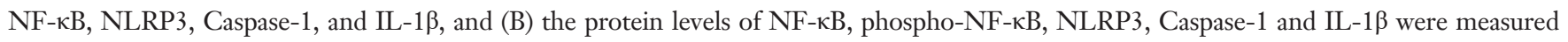

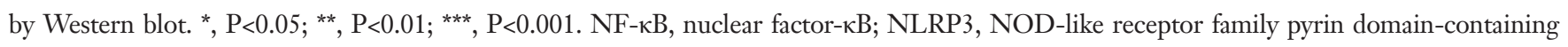
protein 3; HUVECs, human umbilical vein endothelial cells; LPS, lipopolysaccharide; qPCRs, quantitative real-time polymerase chain reactions; IL-1 $\beta$, interleukin- $1 \beta$; NC, negative control.

software (http://www.targetscan.org/) was used to predict the miR-146a-5p target. The prediction results suggested that miR-146a-5p has 3'-UTR binding sites on TRAF6 and IRAK1, both upstream regulators of the NF- $\mathrm{KB}$ signaling pathway. The mRNA and protein levels of TRAF6 and IRAK1 in the HUVECs transfected with the miR-146$5 \mathrm{p}$ mimic or NC were evaluated by qPCRs and western blot assays, respectively. The results showed that TRAF6 and IRAK1 in HUVECs were both down-regulated after transfection with a miR-146-5p mimic compared to the cells transfected with a mimic NC (see Figure $5 A, 5 B$ ). Luciferase reporter assays were used to verify whether miR-146-5p directly targets the 3'-UTR regions of TRAF6 and IRAK1 to regulate their expression. The results revealed that luciferase activity was significantly reduced in cells co-transfected with a miR-146-5p mimic and wild-type TRAF6 or IRAK1 3'UTR compared to luciferase activity in the mimic NC cotransfected cells; however, luciferase activity was not affected by co-transfection with a miR-146-5p mimic and the mutant TRAF6 or IRAK1 3'-UTR (see Figure 5C,5D). 
A

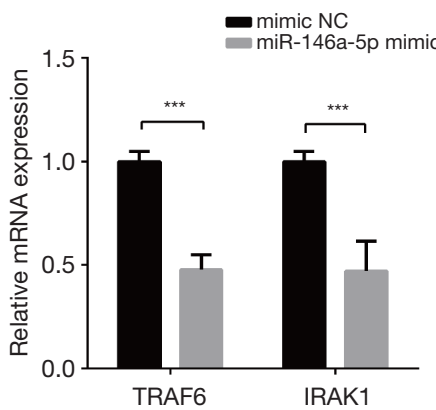

$C \underset{.0}{2.0} \quad \mathbf{E}_{\text {miR-146a-5p mimic }}^{\operatorname{mimic} N C}$
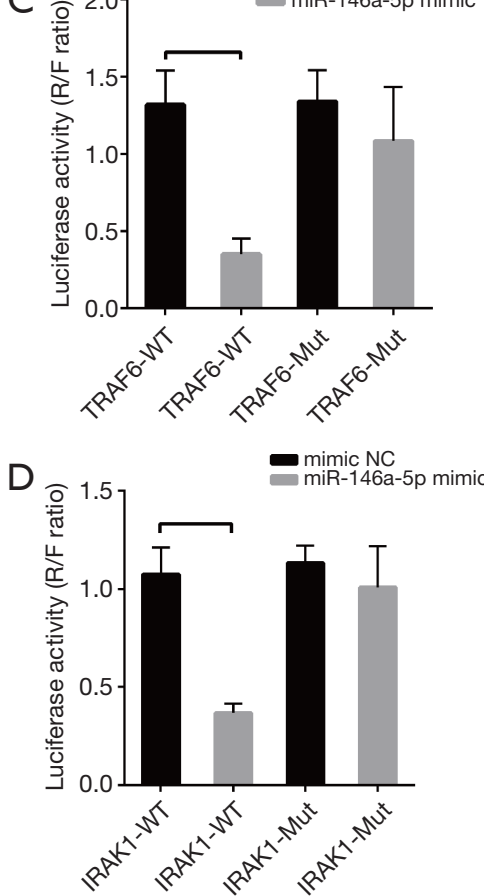

B
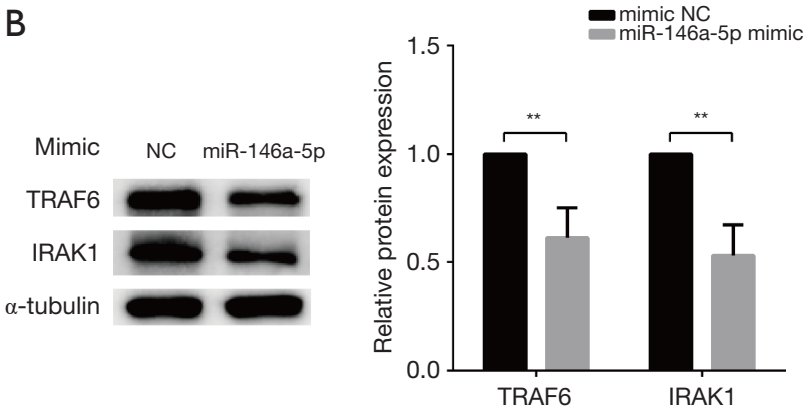

Position 473-480 of Traf6 3' UTR

Traf6 WT 5'...UGCUCUAGAaAgUUGaguUCUCA... 3'

has-miR-146a-5p 3' UUGGGUACCUUAAGUCAAGAGU

Traf6 MUt 5'...UGCUCUAgaAaguUgucaAgagu... 3'

Position 538-545 of Traf6 3' UTR

Traf6 WT 5 '...UCCUUGgaAaACUUAAGUUCUCA... 3'

has-miR-146a-5p 3' UUGGGUACCUUAAGUCAAGAGU 5 ,

Traf6 MUt 5'... UCCUUGgaAaACUUAUCAagagu ... 3'

Position 40-47 of Irak1 3' UTR

Irak1 WT 5'...AAAUCCGGAAGUCAAAGUUCUCA... 3'
has-miR-146a-5p 3 , UUGGGUACCUUAAGUCAAGAGU
Irak1 MUT 5',...AAAUCCGGAAGUCAAUCAAGAGU... 3'

Position 56-63 of Irak1 3' UTR

Irak1 WT 5'...GUUCUCAUGGUCAGAAGUUCUCA ... 3'

has-miR-146a-5p 3' UUGGGUACCUUAAGUCAAGAGU 5,

Irak1 MUT 5'...GUUCUCAUGGUCAGAUCAAGAGU... 3'

Figure 5 MiR-146a-5p down-regulated the NF- $\mathrm{kB} / \mathrm{NLRP} 3$ signaling pathway by targeting the TRAF6 and IRAK1 gene. (A) The mRNA and (B) protein levels of TRAF6 and IRAK1 in the HUVECs transfected with the miR-146a-5p mimic or NC were determined by qPCRs and Western blot analyses, respectively. (C) Luciferase reporter assays were performed using HEK293 cells co-transfected with the miR-146-5p mimic and TRAF6-WT-3'-UTR or TRAF6-Mut-3'-UTR reporter recombinant plasmid. (D) Luciferase reporter assays were performed using HEK293 cells co-transfected with the miR-146-5p mimic and IRAK1-WT-3' UTR or IRAK1-Mut-3'-UTR reporter recombinant plasmid.

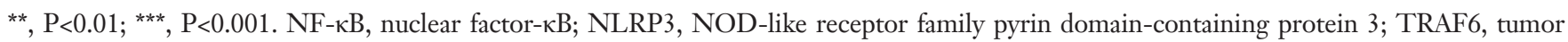
necrosis factor receptor associated factor 6; IRAK1, interleukin-1-receptor-associated kinase 1; HUVECs, human umbilical vein endothelial cells, NC, negative control.

\section{Knockdown of TRAF6- and IRAK1-suppressed LPS-

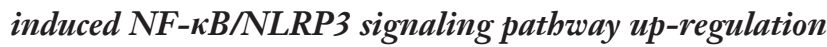 and pro-inflammatory cytokine production}

Finally, we explored the molecular mechanism by which miR-146-5p regulates the NF- $\kappa \mathrm{B} / \mathrm{NLRP} 3$ signaling pathways. The above-mentioned results confirmed that the overexpression of miR-146-5p down-regulated the NF- $\kappa \mathrm{B} / \mathrm{NLRP} 3$ signaling pathways in HUVECs. Next, the cells were transfected with si-TRAF6 or si-IRAK1 for $48 \mathrm{~h}$. The mRNA and protein expression levels of TRAF6 and IRAK1 were significantly reduced after transfection (see Figure $6 A, 6 B)$. We observed that the mRNA expression 

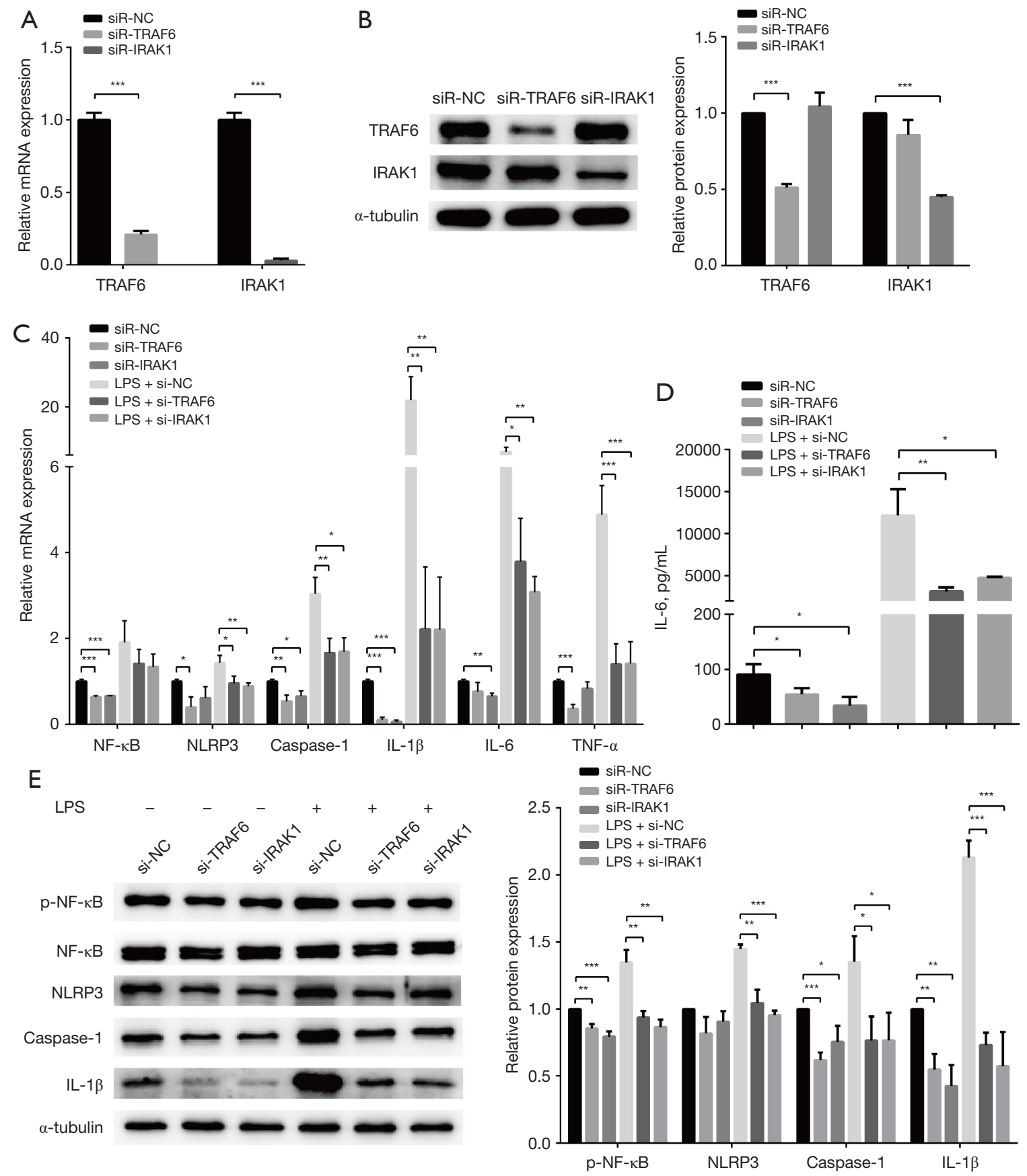

Figure 6 The knockdown of TRAF6 and IRAK1 suppressed LPS-induced NF-кB/NLRP3 signaling pathway up-regulation and proinflammatory cytokine production. The HUVECs transfected with si-TRAF6, si-IRAK1, or si-NC for 48 h, the mRNA (A) and protein (B) expression levels of TRAF6 and IRAK1 were detected. (C) After the knockdown of TRAF6 or IRAK1, the HUVECs were treated with $100 \mathrm{ng} / \mathrm{mL}$ LPS for $24 \mathrm{~h}$, and qPCRs were then used to detect the mRNA expression levels of NF- $\mathrm{B}$, NLRP3, Caspase-1, and proinflammatory cytokine, (D) the secretion level of IL-6 from HUVECs was measured by ELISA, (E) the protein levels of NF- $\kappa B$, phospho-NF$\kappa \mathrm{B}, \mathrm{NLRP} 3$, Caspase-1 and IL-1 $\beta$ were detected by Western blot. *, $\mathrm{P}<0.05$; ** $\mathrm{P}<0.01$; *** $\mathrm{P}<0.001$. TRAF6, tumor necrosis factor receptor

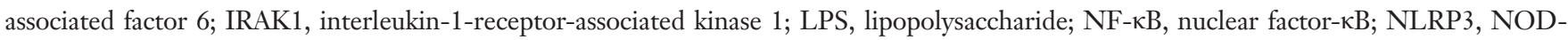
like receptor family pyrin domain-containing protein 3; HUVECs, human umbilical vein endothelial cells; NC, negative control; qPCRs, quantitative real-time polymerase chain reactions; IL-6, interleukin-6; ELISA, enzyme-linked immunoassay; IL-1 $\beta$, interleukin-1 $\beta$. 
levels of NF- $\kappa \mathrm{B}, \mathrm{NLRP} 3$, Caspase-1, and pro-inflammatory cytokine (IL-6, IL-1 $\beta$, and TNF- $\alpha$ ) were all downregulated after TRAF6 or IRAK1 knockdown in the HUVECs regardless of whether the cells were subject to LPS treatment or not (see Figure 6C). The secretion of IL-6 from the HUVECs was found to decline significantly after transfection with si-TRAF6 or si-IRAK1 (see Figure 6D). The western blot analysis revealed that the protein levels of p-NF-кB, NLRP3, Caspase-1, and IL-1 $\beta$ also were significantly reduced by TRAF6 or IRAK1 knockdown (see Figure 6E). These data indicate that miR-146-5p appears to suppress NF- $\kappa \mathrm{B} / \mathrm{NLRP} 3$ signaling pathway and proinflammatory cytokine production by regulating TRAF6 and IRAK1 expression in HUVECs.

\section{Discussion}

Endothelial inflammatory activation in the arterial vasculature is an initiator of the pathobiology of atherosclerotic cardiovascular disease (3). In lesion-prone regions of the artery, the effects of pro-inflammatory agonists, oxidized lipoproteins (ox-LDL), and biomechanical stimulation by disturbed blood flow result in endothelial pro-inflammatory activation. Following by the expression of adhesion molecules, membrane-associated chemokines and prothrombotic mediators are driven in ECs (24-26). The monocytes and lymphocytes then migrate into vessel walls to differentiate into macrophages $(27,28)$. A complex immunoregulatory network is established by the synergistic interaction of cells (including activated endothelium, macrophages, lymphocytes, and smooth muscle cells) in the developing atherosclerotic lesions. Finally, the production of inflammatory cytokines, growth factors, and reactive oxygen species (ROS) in the lining of the arterial vasculature perpetuates a chronic pro-inflammatory state and promotes the progression of atherosclerosis $(3,29)$. Thus, reducing the endothelial pro-inflammatory activation could serve as a therapeutic strategy for atherosclerosis. In this study, we constructed an inflammatory response in HUVECs by LPS stimulation to mimic the inflammatory injury that occurs during AS. Further experiments revealed that miR-146a-5p overexpression repressed LPS-mediated pro-inflammatory cytokine production by regulating the activation of the NF$\kappa \mathrm{B}$ and NLRP3 signaling pathways. Finally, we confirmed that miR-146a-5p suppressed the NF-кB/NLRP3 signaling pathway by targeting TRAF6 and IRAK1 3'-UTR. The results revealed that increasing miR-146a-5p levels might be a novel strategy for the prevention and treatment of AS.

A number of pathophysiologic stimuli signal for proinflammatory activation in the arterial endothelium are predominantly through activating the pleiotropic transcription factor NF- $\mathrm{KB}$, which leads to the expression of multiple pro-inflammatory and pro-adhesive genes in ECs (30-32). NF- $\kappa \mathrm{B}$ signaling is thought to play a vital role in the activation of endothelial inflammation during atherosclerosis. The activity of NF- $\mathrm{\kappa B}$ is mainly dependent on its phosphorylation and nuclear translocation (33). Research suggests that the selective inhibition of NF- $\mathrm{kB}$ in ECs reduces and stabilizes atherosclerotic plaques in mice models. The mechanism is associated with the decreased recruitment of macrophages, which occurs by reducing the adhesion molecules and pro-inflammatory cytokine expression $(32,34)$. MiR-146a has been shown to inhibit $\mathrm{NF}-\kappa \mathrm{B}$ phosphorylation to negatively regulate LPS-induced inflammatory cytokine production in ECs (35). Similarly, we found miR-146a-5p overexpression repressed the level of phospho-NF- $\mathrm{KB}$ in HUVECs, resulting in a significant decrease in pro-inflammatory cytokine expression and secretion. The results revealed that miR-146a-5p can reduce the expression of pro-inflammatory factors by inhibiting $\mathrm{NF}-\kappa \mathrm{B}$ activation, and that enhancing the expression of miR-146a-5p might antagonize atherosclerosis.

NLRP3 inflammasome, an intracellular complex, which cleave pro-caspase- 1 to active caspase- 1 , and then converts pro-IL-1 $\beta$ and pro-IL-18 to its mature forms (36). NLRP3 inflammasome can be activated by many danger signals, such as oxidative stress, mitochondrial dysfunction, lysosome rupture, and ox-LDL, which are linked to an increased risk of AS. Studies had suggested that NLRP3 is up-regulated in the atherosclerotic plaques of AS patients, and is related to the severity and prognosis of AS $(37,38)$. The inhibition of NLRP3 signaling reduced pro-inflammatory cytokine production and led to plaque stabilization in mice with AS (39). Those researches revealed that NLRP3 inflammasome contributes to the progression of atherosclerosis, and silencing it results in the stabilization of atherosclerotic plaque. Several miRNA had been implicated in regulating the expression and activation of the NLRP3 inflammasome. Zhou et al. confirmed that miR-495 suppressed the NLRP3 inflammasome signaling 
pathway by targeting NLRP3 3 '-UTR (40). MiR-223 and miR-374a-5p were also found to have a negative regulatory effect on the activation of NLRP3 inflammatory signals $(41,42)$. In addition, the expression of NLRP 3 and IL- $1 \beta$ has proven to be regulated by NF- $\kappa \mathrm{B}$ activation $(43,44)$. In the present study, we observed that miR-146a-5p repressed the NLRP3 inflammasome signaling pathway and proinflammatory cytokine production by decreasing the phospho-NF- $\mathrm{kB}$ level in ECs.

TRAF6 and IRAK1, which are multifunctional signal transduction molecules, are thought to play an essential role in the activation of the NF- $\mathrm{\kappa B}$ signaling pathway and the regulation of inflammation. NF- $\kappa \mathrm{B}$ activation depends on the recruitment of TRAF6 to IRAK1 and subsequent complex formation $(31,45)$. Studies have confirmed that TRAF6 and IRAK1 were regulated by multiple miRNAs. Overexpressed miR-2187 was found to reduce inflammatory factor production and antiviral genes by targeting TRAF6 to avoid an excessive inflammatory response (46). Elevated miR-223 inhibited the pro-inflammatory response by downregulating IRAK-1 in macrophages (47). Studies had shown that $\mathrm{miR}-146 \mathrm{a}-5 \mathrm{p}$ inhibited the proliferation, invasion, and migration of human breast cancer cells and suppressed the epithelial-mesenchymal transition of trophoblasts by directly reducing IRAK1 and TRAF6 expression at the post-transcriptional level $(48,49)$. However, there have been rare reports of miR-146a-5p regulating the downstream signaling pathways by directly targeting TRAF6 and IRAK1 in vascular ECs. Thus, luciferase reporter assays and molecular biology experiments were performed in this study, and similar to previous findings, we found that miR146a-5p directly targeted TRAF6 and IRAK1 genes to reduce NF- $\mathrm{NB}$ activation and the NLRP3 inflammasome level in HUVECs.

To confirm the contribution of TRAF6 and IRAK1 regulation on the activation of the NF- $\mathrm{B} / \mathrm{NLRP} 3$ inflammasome signaling pathway, si-TRAF6 and siIRAK1 were transfected into HUVECs to knockdown the expression of TRAF6 and IRAK1, respectively. We further observed that the expression levels of $\mathrm{p}-\mathrm{NF}-\kappa \mathrm{B}$, NLRP3, Caspase-1, pro-inflammatory cytokine (IL-6, IL$1 \beta$, and TNF- $\alpha$ ), and the secretion of IL- 6 were all downregulated following TRAF6 or IRAK1 knockdown in HUVECs regardless of whether the cells were subject to LPS treatment or not. Previous research has indicated that TRAF6 or IRAK1 knockdown inhibited pro-inflammatory cytokine secretion by limiting the levels of phospho-NF$\kappa \mathrm{B}(18)$, and our results were consistent with those previous studies. Our data indicated that miR-146-5p appeared to alleviate NF- $\mathrm{KB} / \mathrm{NLRP} 3$ signaling pathway and proinflammatory cytokine production by regulating TRAF6 and IRAK1 expression in HUVECs.

It is well known that miRNAs are important regulators of the pathophysiological cellular effects and molecular signaling pathways involved in atherosclerosis. Numerous studies have shown that miRNAs alter the balance of atherosclerotic plaque progression by regulating the cellular adhesion, proliferation, lipid uptake, and efflux, and the generation of inflammatory mediators (50). Studies have highlighted that miR-181b and miR-146a, as cytokineresponsive and atheroprotective miRNAs, regulate EC inflammation and plaque progression by targeting NF$\kappa \mathrm{B}$ signaling (51). MiR-126 has been shown to inhibit the expression of vascular adhesion molecule-1 (VCAM-1) to limit leukocyte adhesion in ECs (52). MiR-33 has been shown to target the cholesterol transporter $\mathrm{ABC}$ transporter A1 (ABCA1) to repress cholesterol efflux and promote the progress of AS (53). Our findings revealed that miR-146a$5 p$ overexpression in HUVECs repressed LPS-mediated NF-кB/NLRP3 signaling pathway and pro-inflammatory cytokines production by regulating the IRAK1 and TRAF6. Similarly, a previous study showed that miR-146a-5p repressed chronic constriction injury-induced mechanical and thermal hyperalgesia by targeting IRAK1 and TRAF6 in neurons (54). MiR-146a-5p has also been reported to suppress LPS-mediated pro-inflammatory cytokine production and cell activation of human hepatic stellate cells by down-regulating TRAF6 expression (18).

In conclusion, this study showed that miR-146a$5 \mathrm{p}$, as a regulator of TRAF6 and IRAK 1 expression, alleviated the LPS-induced activation of the NF- $\kappa \mathrm{B} /$ NLRP3 inflammasome signaling pathway, and reduced the production of pro-inflammatory cytokines in HUVECs. The findings of this study have been depicted in a schematic illustration (see Figure 7). Overall, our results increase understandings of miR-146a-5p function, and provide insights into the regulatory network of miR-146a-5pmediated immune responses against endothelial proinflammatory activation and dysfunction. Further animal model investigations examining the anti-inflammatory and anti-atherosclerotic effects of miR-146a-5p in regulating activation of NF- $\mathrm{NB} / \mathrm{NLRP} 3$ inflammasome should be 


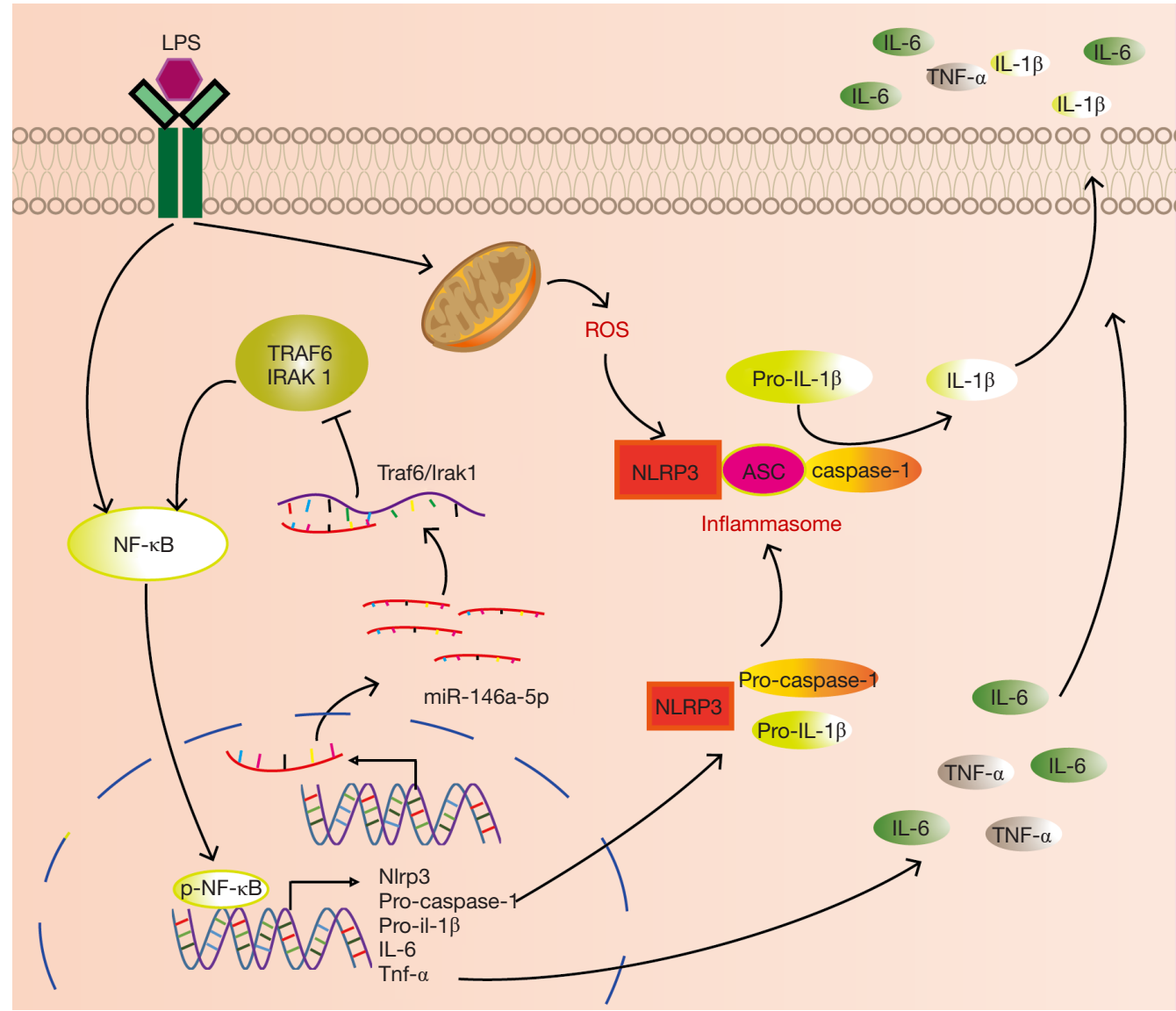

Figure 7 Schematic illustration of the current working hypothesis. MiR-146a-5p inhibited LPS-induced NF- $\kappa$ B/NLRP3 pathway proteins, including p-NF- $\mathrm{B}$, NLRP3, Caspase-1, and IL-1 $\beta$. In particular, miR-146a-5p showed anti-inflammatory effects by targeting TRAF6 and IRAK1. Summarily, miR-146a-5p alleviated LPS-induced inflammation injury via the regulation of TRAF6 and IRAK1 in HUVECs. LPS,

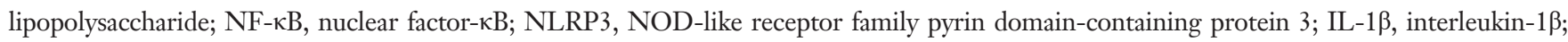
TRAF6, tumor necrosis factor receptor associated factor 6; IRAK1, interleukin-1-receptor-associated kinase 1; HUVECs, human umbilical vein endothelial cells.

conducted in the future.

\section{Acknowledgments}

The authors would like to thank other colleagues whom were not listed in the authorship of Research Experimental Center, Meizhou People's Hospital (Huangtang Hospital), for their helpful comments on the manuscript.

Funding: This work was supported by grants from the National Natural Science Foundation for Young Scientists of China (82002216 and 82000410), the Medical Scientific Research Foundation of Guangdong Province (A2020418 and A2021144), the Guangdong Provincial Key Laboratory of Precision Medicine and Clinical Translation Research of Hakka Population (2018B030322003), and the Scientific Research and Cultivation Project of Meizhou People's Hospital (PY-A2019001, PY-C2019013, and PYC2021010).

\section{Footnote}

Reporting Checklist: The authors have completed the MDAR reporting checklist. Available at https://dx.doi. org/10.21037/atm-21-3903 
Data Sharing Statement: Available at https://dx.doi. org/10.21037/atm-21-3903

Conflicts of Interest: All authors have completed the ICMJE uniform disclosure form (available at https://dx.doi. org/10.21037/atm-21-3903). ZZ reports support for the present manuscript from Scientific Research and Cultivation Project of Meizhou People's Hospital (grants no. PYA2019001). SL reports support for the present manuscript from National Natural Science Foundation for Young Scientists of China (grants no. 82000410). QD reports support for the present manuscript from Medical Scientific Research Foundation of Guangdong Province (grants no. A2021144) and Scientific Research and Cultivation Project of Meizhou People's Hospital (grants no. PY-C2021010). $\mathrm{JH}$ reports support for the present manuscript from National Natural Science Foundation for Young Scientists of China (grants no. 82002216), Medical Scientific Research Foundation of Guangdong Province (grants no. A2020418), and Scientific Research and Cultivation Project of Meizhou People's Hospital (grants no. C2019013). The other authors have no conflicts of interest to declare.

Ethical Statement: The authors are accountable for all aspects of the work in ensuring that questions related to the accuracy or integrity of any part of the work are appropriately investigated and resolved. The present study was approved by the Ethics Committee for Research of Meizhou People's Hospital (No. 2018-C-11) and was conducted in accordance with the Declaration of Helsinki (as revised in 2013). All patients signed an informed consent before participating in the study.

Open Access Statement: This is an Open Access article distributed in accordance with the Creative Commons Attribution-NonCommercial-NoDerivs 4.0 International License (CC BY-NC-ND 4.0), which permits the noncommercial replication and distribution of the article with the strict proviso that no changes or edits are made and the original work is properly cited (including links to both the formal publication through the relevant DOI and the license). See: https://creativecommons.org/licenses/by-nc-nd/4.0/.

\section{References}

1. Roth GA, Forouzanfar MH, Moran AE, et al. Demographic and epidemiologic drivers of global cardiovascular mortality. N Engl J Med 2015;372:1333-41.
2. Libby P, Buring JE, Badimon L, et al. Atherosclerosis. Nat Rev Dis Primers 2019;5:56.

3. Gimbrone MA, Jr., García-Cardeña G. Endothelial Cell Dysfunction and the Pathobiology of Atherosclerosis. Circ Res 2016;118:620-36.

4. Mai W, Liao Y. Targeting IL-1 $\beta$ in the Treatment of Atherosclerosis. Front Immunol 2020;11:589654.

5. He L, Weng H, Li Q, et al. Lactucopicrin Inhibits

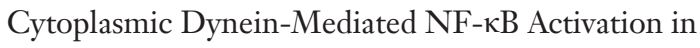
Inflammated Macrophages and Alleviates Atherogenesis in Apolipoprotein E-Deficient Mice. 2021;65:e2000989.

6. He Y, Hara H, Núñez G. Mechanism and Regulation of NLRP3 Inflammasome Activation. Trends Biochem Sci 2016;41:1012-21.

7. Stutz A, Golenbock DT, Latz E. Inflammasomes: too big to miss. J Clin Invest 2009;119:3502-11.

8. Duewell P, Kono H, Rayner KJ, et al. NLRP3 inflammasomes are required for atherogenesis and activated by cholesterol crystals. Nature 2010;464:1357-61.

9. Samstad EO, Niyonzima N, Nymo S, et al. Cholesterol crystals induce complement-dependent inflammasome activation and cytokine release. J Immunol 2014;192:2837-45.

10. Rhoads JP, Lukens JR, Wilhelm AJ, et al. Oxidized Low-Density Lipoprotein Immune Complex Priming of the Nlrp3 Inflammasome Involves TLR and Fc $\gamma R$ Cooperation and Is Dependent on CARD9. J Immunol 2017;198:2105-14.

11. Takahashi M. NLRP3 inflammasome as a key driver of vascular disease. Cardiovasc Res 2021. [Epub ahead of print]. doi: $10.1093 / \mathrm{cvr} / \mathrm{cvab010}$.

12. Bartel DP. MicroRNAs: target recognition and regulatory functions. Cell 2009;136:215-33.

13. Krol J, Loedige I, Filipowicz W. The widespread regulation of microRNA biogenesis, function and decay. Nat Rev Genet 2010;11:597-610.

14. Constantin L, Constantin M, Wainwright BJ. MicroRNA Biogenesis and Hedgehog-Patched Signaling Cooperate to Regulate an Important Developmental Transition in Granule Cell Development. Genetics 2016;202:1105-18.

15. Katsaraki K, Karousi P, Artemaki PI, et al. MicroRNAs: Tiny Regulators of Gene Expression with Pivotal Roles in Normal B-Cell Development and B-Cell Chronic Lymphocytic Leukemia. Cancers (Basel) 2021;13:593.

16. Mehta A, Baltimore D. MicroRNAs as regulatory elements in immune system logic. Nat Rev Immunol 2016;16:279-94.

17. Fridrichova I, Zmetakova I. MicroRNAs Contribute to Breast Cancer Invasiveness. Cells 2019;8:1361. 
18. Chen Y, Zeng Z, Shen X, et al. MicroRNA-146a5 p Negatively Regulates Pro-Inflammatory Cytokine Secretion and Cell Activation in Lipopolysaccharide Stimulated Human Hepatic Stellate Cells through Inhibition of Toll-Like Receptor 4 Signaling Pathways. Int J Mol Sci 2016;17:1076.

19. Taganov KD, Boldin MP, Chang KJ, et al. NF-kappaBdependent induction of microRNA miR-146, an inhibitor targeted to signaling proteins of innate immune responses. Proc Natl Acad Sci U S A 2006;103:12481-6.

20. Menghini R, Casagrande V, Marino A, et al. MiR-216a: a link between endothelial dysfunction and autophagy. Cell Death Dis 2014;5:e1029.

21. Schober A, Weber C. Mechanisms of MicroRNAs in Atherosclerosis. Annu Rev Pathol 2016;11:583-616.

22. Demkes CJ, van Rooij E. MicroRNA-146a as a Regulator of Cardiac Energy Metabolism. Circulation 2017;136:762-4.

23. Thygesen K, Alpert JS, Jaffe AS, et al. Third universal definition of myocardial infarction. Circulation 2012;126:2020-35.

24. Steinberg D, Witztum JL. Oxidized low-density lipoprotein and atherosclerosis. Arterioscler Thromb Vasc Biol 2010;30:2311-6.

25. Zhong T, Li Y, He X, et al. Adaptation of endothelial cells to shear stress under atheroprone conditions by modulating internalization of vascular endothelial cadherin and vinculin. Ann Transl Med 2020;8:1423.

26. Noguchi N, Jo H. Redox going with vascular shear stress. Antioxid Redox Signal 2011;15:1367-8.

27. Eid RE, Rao DA, Zhou J, et al. Interleukin-17 and interferon-gamma are produced concomitantly by human coronary artery-infiltrating $\mathrm{T}$ cells and act synergistically on vascular smooth muscle cells. Circulation 2009;119:1424-32.

28. Escárcega RO, Lipinski MJ, García-Carrasco M, et al. Inflammation and atherosclerosis: Cardiovascular evaluation in patients with autoimmune diseases. Autoimmun Rev 2018;17:703-8.

29. Fan J, Watanabe T. Inflammatory reactions in the pathogenesis of atherosclerosis. J Atheroscler Thromb 2003;10:63-71.

30. Collins T, Cybulsky MI. NF-kappaB: pivotal mediator or innocent bystander in atherogenesis? J Clin Invest 2001;107:255-64.

31. Ben J, Jiang B, Wang D, et al. Major vault protein suppresses obesity and atherosclerosis through inhibiting IKK-NF- $\kappa \mathrm{B}$ signaling mediated inflammation. Nat
Commun 2019;10:1801.

32. Gareus R, Kotsaki E, Xanthoulea S, et al. Endothelial cell-specific NF-kappaB inhibition protects mice from atherosclerosis. Cell Metab 2008;8:372-83.

33. Jayakumar T, Hou SM, Chang CC, et al. Columbianadin Dampens In Vitro Inflammatory Actions and Inhibits Liver Injury via Inhibition of NF- $\kappa \mathrm{B} / \mathrm{MAPKs}$ : Impacts on -OH Radicals and HO-1 Expression. Antioxidants (Basel) 2021;10:553.

34. Song D, Fang G, Mao SZ, et al. Selective inhibition of endothelial NF- $\mathrm{NB}$ signaling attenuates chronic intermittent hypoxia-induced atherosclerosis in mice. Atherosclerosis 2018;270:68-75.

35. Xiao Q, Zhu X, Yang S, et al. LPS induces CXCL16 expression in HUVECs through the miR-146a-mediated TLR4 pathway. Int Immunopharmacol 2019;69:143-9.

36. Grebe A, Hoss F, Latz E. NLRP3 Inflammasome and the IL-1 Pathway in Atherosclerosis. Circ Res 2018;122:1722-40.

37. Afrasyab A, Qu P, Zhao Y, et al. Correlation of NLRP3 with severity and prognosis of coronary atherosclerosis in acute coronary syndrome patients. Heart Vessels 2016;31:1218-29.

38. Shi X, Xie WL, Kong WW, et al. Expression of the NLRP3 Inflammasome in Carotid Atherosclerosis. J Stroke Cerebrovasc Dis 2015;24:2455-66.

39. Zheng F, Xing S, Gong Z, et al. Silence of NLRP3 suppresses atherosclerosis and stabilizes plaques in apolipoprotein E-deficient mice. Mediators Inflamm 2014;2014:507208.

40. Zhou T, Xiang DK, Li SN, et al. MicroRNA-495 Ameliorates Cardiac Microvascular Endothelial Cell Injury and Inflammatory Reaction by Suppressing the NLRP3 Inflammasome Signaling Pathway. Cell Physiol Biochem 2018;49:798-815.

41. Xu D, Zhang X, Chen X, et al. Inhibition of miR-223 attenuates the NLRP3 inflammasome activation, fibrosis, and apoptosis in diabetic cardiomyopathy. Life Sci 2020;256:117980.

42. Chen Z, Hu Y, Lu R, et al. MicroRNA-374a-5p inhibits neuroinflammation in neonatal hypoxic-ischemic encephalopathy via regulating NLRP3 inflammasome targeted Smad6. Life Sci 2020;252:117664.

43. Abais JM, Xia M, Zhang Y, et al. Redox regulation of NLRP3 inflammasomes: ROS as trigger or effector? Antioxid Redox Signal 2015;22:1111-29.

44. Qiao Y, Wang P, Qi J, et al. TLR-induced NF-кB activation regulates NLRP3 expression in murine 
macrophages. FEBS Lett 2012;586:1022-6.

45. Deng L, Wang C, Spencer E, et al. Activation of the IkappaB kinase complex by TRAF6 requires a dimeric ubiquitin-conjugating enzyme complex and a unique polyubiquitin chain. Cell 2000;103:351-61.

46. Gao W, Chang R, Sun Y, et al. MicroRNA-2187 Modulates the NF- $\kappa \mathrm{B}$ and IRF3 Pathway in Teleost Fish by Targeting TRAF6. Front Immunol 2021;12:647202.

47. Wang J, Wu J, Cheng Y, et al. Over-expression of microRNA-223 inhibited the proinflammatory responses in Helicobacter pylori-infection macrophages by downregulating IRAK-1. Am J Transl Res 2016;8:615-22.

48. Long JP, Dong LF, Chen FF, et al. miR-146a-5p targets interleukin-1 receptor-associated kinase 1 to inhibit the growth, migration, and invasion of breast cancer cells. Oncol Lett 2019;17:1573-80.

49. Ding J, Zhang Y, Cai X, et al. Extracellular vesicles derived from M1 macrophages deliver miR-146a-5p and miR-

Cite this article as: Hou J, Deng Q, Deng X, Zhong W, Liu S, Zhong Z. MicroRNA-146a-5p alleviates lipopolysaccharideinduced NLRP3 inflammasome injury and pro-inflammatory cytokine production via the regulation of TRAF6 and IRAK1 in human umbilical vein endothelial cells (HUVECs). Ann Transl Med 2021;9(18):1433. doi: 10.21037/atm-21-3903 146b-5p to suppress trophoblast migration and invasion by targeting TRAF6 in recurrent spontaneous abortion. Theranostics 2021;11:5813-30.

50. Feinberg MW, Moore KJ. MicroRNA Regulation of Atherosclerosis. Circ Res 2016;118:703-20.

51. Sun X, Belkin N, Feinberg MW. Endothelial microRNAs and atherosclerosis. Curr Atheroscler Rep 2013;15:372.

52. Harris TA, Yamakuchi M, Ferlito M, et al. MicroRNA-126 regulates endothelial expression of vascular cell adhesion molecule 1. Proc Natl Acad Sci U S A 2008;105:1516-21.

53. Rayner KJ, Sheedy FJ, Esau CC, et al. Antagonism of miR-33 in mice promotes reverse cholesterol transport and regression of atherosclerosis. J Clin Invest 2011;121:2921-31.

54. Wang Z, Liu F, Wei M, et al. Chronic constriction injuryinduced microRNA-146a-5p alleviates neuropathic pain through suppression of IRAK1/TRAF6 signaling pathway. J Neuroinflammation 2018;15:179. 